\title{
Un apunte sobre la necesidad de autocrítica
}

\author{
Rafael Caballero Sánchez \\ Profesor Titular de Derecho Administrativo de la Universidad Complutense \\ r.caballero.sanch@gmail.com
}

En las ponencias e intervenciones (magníficas) del seminario sobre la reforma del Estado llegué a escuchar hasta en dos ocasiones una crítica dirigida a los economistas, que comparto plenamente: son profetas del pasado, pero no nos ayudan a prevenir los errores del futuro. Son capaces de explicar científicamente y con rotundidad las raíces de la lacerante crisis económica en la que nos hemos sumergido, pero lo hacen a toro pasado, con la seguridad de quien conoce el desenlace de una película. Si con tanta vehemencia nos muestran ahora por qué fuimos abocados a un precipicio de difícil salida ¿por qué no fueron capaces de anticiparse y predecir un desenlace fatal que nos hubiera ahorrado tantos disgustos?.

En la misma dirección, los juristas debemos aplicar una dosis suficiente de autocrítica sobre el papel que estamos llamados a desempeñar en la regeneración y reorientación de un modelo que ofrece signos evidentes de agotamiento y de insuficiencia de recursos apropiados para producir respuestas y soluciones a los problemas planteados. Aun a riesgo de incurrir en el mismo defecto que pongo de manifiesto, quiero poner de relieve la facilidad con que nuestros análisis y comentarios son más descriptivos y críticos de lo que ha ocurrido, que propositivos y constructivos de lo que haya que hacer para salir adelante. Es fácil hacer sangre de lo que no funciona, del lamentable estado de nuestra legislación, del limitado alcance y enfoque de las reformas que se hacen, del precario nivel de nuestros políticos y gobernantes, pero no es tan sencillo acertar con el camino de salida a esa situación. Sin duda es positivo el análisis de la realidad, la identificación de las cuestiones que no están resueltas, y la sistematización de los datos obtenidos en esa observación. Pero, por un lado ¿por qué no supimos en su momento ofrecer un diseño más cabal que previniese la hecatombe actual? Y, por otro, ¿qué mecanismos son los adecuados para reconducir la crisis actual?

En este sentido, el objetivo del seminario y del espíritu que lo sustenta no puede ser más acertado: dar voz a la academia y a los juristas para aportar soluciones en este estado de emergencia en el que parece que nos encontramos. Pero hay que hacerlo siendo conscientes del peligro que tenemos de caer en exceso en el lamento y la denuncia de la crisis institucional y económica actual y de las tibias medidas ensayadas para superarla, sin llegar a aportar realmente alternativas bien construidas y sustentadas, más allá de directrices tan incuestionables como insuficientes.

En el seminario se escucharon ideas muy sugerentes e incluso brillantes sobre la situación en la que nos encontramos (la soberanía de los Estados de la UE es hoy inversamente proporcional al nivel de la prima de riesgo de la deuda de cada Estado; está cristalizando un derecho constitucional europeo sin Constitución formal, a diferencia de las Constituciones nacionales sin derecho constitucional material de los Estados; las reformas de calado en Europa -verdadero hard law- se están adoptando a través del soft law comunitario; asistimos a la progresiva fractura entre Estados acreedores y deudores dentro de la Unión; el Estado se ha debilitado frente a la sociedad, lo cual se plasma entre otras cosas en la sustitución progresiva de la ley por el contrato en los distintos órdenes de decisión jurídica), pero no tanto se aportaron predicciones de lo que pueda pasar en un futuro más o menos próximo ni propuestas de salida viables y definidas. Sin duda hay que partir una lanza en defensa del Estado de Derecho y hay que restar dramatismo a una necesaria reforma y puesta al día de la Constitución, como señal precisamente de madurez constitucional, pero no es nada sencillo concretar en qué debe consistir la una y la otra. 
Lamentablemente, esa vertiente positiva o de respuesta tiene un alcance limitado por el hecho de que corresponde al poder político tomar las decisiones oportunas. Podemos discrepar de la concreción que los gobernantes dan a los nuevos paradigmas de la racionalidad, la racionalización y la sostenibilidad, pero son ellos los que tienen la competencia y la responsabilidad para establecer aquí y ahora qué es racional y sostenible, y para cambiarlo si lo entienden necesario, siempre que lo hagan con respeto a las reglas del Derecho (por el instrumento adecuado, sin carácter retroactivo...) y que no se salgan del halo de su legítima discrecionalidad. Es decir, se deben depurar las decisiones normativas o ejecutivas que sean claramente irracionales o insostenibles, pero no corresponde al jurista reemplazar al político en la determinación, por ejemplo, del umbral de la sostenibilidad financiera y en la decisión de incorporar los índices de morosidad en la medición de la capacidad de los entes públicos para adoptar compromisos financieros. Como es natural, no es la misma la discrecionalidad decisoria de cada instancia de poder. Pero especialmente en el caso del legislador, el límite es más bien negativo, quedándole vetado solo lo que no sea razonable y no tenga cabida en la Constitución.

El círculo vicioso del desencanto se cierra con una simple mirada al panorama de nuestros gobernantes, en sus distintos órdenes y colores, que son quienes deben adoptar las decisiones de reforma y verdadera reconstrucción, dejándose orientar y aconsejar por el criterio experto y sabio de los estudiosos del derecho, la economía, la gestión pública y la sociedad. Pero la falta de sentido de Estado, con mayúscula, y de verdadera vocación de servicio al interés general, tanto de quienes ejercen el poder político como de quienes representan en cada momento la oposición, y la miseria y podredumbre de la política, en cursiva, lo contaminan todo en la vida pública de este país. 